\author{
Ivonete da Silva ${ }^{1}$, Elizabete Lucas $^{2}$ and Francisca de Franca ${ }^{3}$
}

\title{
STUDY OF CONDITIONS FOR POLYACRYLAMIDE USE IN PETROLEUM RESERVOIRS: PHYSICAL FLOW SIMULATION IN POROUS media
}

\author{
${ }^{1}$ PETROBRAS Research Center, Ilha do Fundao, Q 7, 21949-900, Rio de J aneiro, Brazil \\ 2 Federal University of Rio de Janeiro, Institute of M acromolecules, Ilha do Fundao, 21945-970, \\ Rio de Janeiro, Brazil \\ ${ }^{3}$ Federal University of Rio de J aneiro, Technology Center, Bloco E, Av. Horacio de M acedo, \\ 2030, Ilha do Fundao, 21949-909 Rio de Janeiro, RJ , Brazil \\ ivonetegonzalez@petrobras.com.br, elucas@ima.ufrj.br,.fpfranca@eq.ufrj.com.br
}

Received: April 10, 2009

(c) Da Silva I., Lucas E., De Franca F., 2010

\begin{abstract}
This article describes the reservoir's average shear rate calculation and the rheological study of the polymer dispersion under the target reservoir conditions. It also identifies and quantifies the rock-fluid interaction parameters with this reservoir, including the total adsorption, residual resistance factor. The results confirm that the selected polymer is suitable to the target reservoir.
\end{abstract}

Keywords: polymer, polyacrylamide, oil recovery, physical simulation, rock-fluid interaction, total adsorption, rheology.

\section{Introduction}

The objective of injection polymer projects is to increase the oil recovery factor by reducing the mobility ratio between the displacement (water) and displaced (oil) fluids. This is achieved by increasing the aqueous phase viscosity, thereby improving the sweep efficiency and, as a result, the oil recovery [1-5]. The injected polymer does not reduce the residual oil saturation, that is, it does not act on the displacement efficiency. It simply works on the swept efficiency, allowing the residual oil saturation to be reached more quickly or more economically [6]. Moreover, the injected fluid viscosity increase promotes an advance front saturation increase of this fluid, which also accelerates the oil production output [7-11].

The polymer flooding process is relatively simple. However, the success of the application involves many variables and uncertainties, such as the shear rate, the remaining oil volume and the reservoir hydrodynamics. Thus, the application planning involves several phases including a meticulous laboratory study before the field phase [1, 2, 12-18].

Petrobras' first experience with polymers was in 1969 in the Carmopolis/SE Field [19-21], in the so called
"Pusher" project with the polymer injection being in the main block that lasted up to 1972 . The final evaluation of this project was only made in 1989 by CENPES PETROBRAS Research Center [11], generating many controversial opinions as to whether the process was a success or not. Many doubts were raised at that time; among them the correct quantity of the injected polymer, its solubility, the operational ability of the surface equipment such as, pumps, dosage measurers and mixers, even the evaluation data reliability itself. Years later, in spite of the discussion, this experience, together with the process attractiveness, expanded even more by the technological advantages achieved by the polymers since then, encouraged Petrobras to invest in three new mobility correction projects, using polymers $[7,8,11]$.

This is the second stage of an application study in a Northeast Brazilian field. The first stage, previously presented [10], included the reservoir evaluation as a candidate for polymer fluid injection. The evaluation was judged on the prerequisites found in the literature [13-18] and the polymer pre-selection was based on the market choice, cost and availability and its physicochemical characteristics criteria $[1,2]$.

Here the laboratory evaluation methodology to select the polymer under the specific target field conditions is explained. The polymer evaluation was made under simulated application real conditions: rock, fluids, chemical products, temperature, and flow condition. Thereby, the polymer rock-flow interaction parameters with the reservoir were identified and quantified. This included the total adsorption and residual resistance factor. The obtained data confirmed the polymer suitability to the reservoir and was the input for the design stage of the injected polymer slug. 


\section{Experimental}

\subsection{M aterials}

Three commercial samples of polyacrylamide with different hydrolysis degree were used: Flopaan $3230 \mathrm{~S}$, with $20 \%, 25 \%$ and $30 \%$. All samples, kindly supplied by Floerger, France, were in powder form and $99 \%$ pure. Other solvents and chemical products were also used. Glacial acetic acid P.A. and sodium hypochlorite (5\% pure) were supplied by Merck. PETROBRAS - the Brazilian Petroleum Company - kindly supplied the Brazilian reservoir rock samples.

\subsection{M ethods}

The experimental description initially covers the specification of the shear rate in the reservoir for correlation with the viscosity measurements carried out under laboratory conditions. This is followed by a rheological study of the previously selected polymer at the target reservoir temperature, and in a shear rate range that covers the reservoir typical values. Finally, this polymer is subjected to a physical flow simulation under the target reservoir conditions to determine rock-fluid interaction parameters (total adsorption and residual resistance factor).

The objective of the laboratory tests was to prove the performance of the partially hydrolyzed polyacrylamide Flopaam 3230s as thickener of the injection water under the physicochemical conditions of the reservoir located in Carmopolis, Brazil. This reservoir produces oil with viscosity in the range of $30-50 \mathrm{cP}(323 \mathrm{~K})$ and 22 API. The objective of the rheological study was to find the lowest polymer concentration that would achieve the same or close viscosity to that of the oil in the reservoir conditions (shear rate, temperature and injection water) to form a uniform advancing front and improve the swept efficiency of the target field.

Initially the compositions of the injection and produced waters were analyzed with the standard methods, presented in the Table 1.

The geometric data were obtained using paquimeter. The porosity was analyzed in the porosimeter Corelab. The rock permeabilities, saturations and rock-flow interaction parameters were measured in the flow system.

\subsubsection{Defining the shear rate in the reservoir}

A reservoir average shear rate calculation is highly discussed in engineering circles and there have been several papers published extolling the different correlations developed for this purpose $[1,2,6]$. By using these correlations, an estimated shear rate of $10 \mathrm{~s}^{-1}$ is offered as a typical average value for a reservoir.. In this study, the respective shear rates were calculated for the polymeric solution flowing from the surface equipment (Eq. 1) until the porous media (Eq. 2).

1) In the pipelines and restrictions:

$$
\gamma=4 \mathrm{Q} / \pi \mathrm{R}^{3}
$$

where: $Q$ is the flow rate, $\mathrm{m}^{3} / \mathrm{s} ; R$ is radius, $\mathrm{m} ; \gamma$ is the shear rate, $\mathrm{s}^{-1}$

The shear rate in the pipeline is $5900 \mathrm{~s}^{-1}$, based on Eq. (1), assuming that: 1) flow rate is $50 \mathrm{~m}^{3} / \mathrm{d}$ (corresponding to the selected area in the target reservoir); 2) pipeline diameter is 2 inches, approximately $5 \mathrm{~cm}$.

2) In the reservoir:

$$
\gamma=70.94 \mathrm{Q} /\left(\mathrm{Rh}(\phi \mathrm{Kw})^{0.5}\right)
$$

where: $Q$ is the flow rate, $\mathrm{m}^{3} / \mathrm{s} ; R$ is radius, $\mathrm{m} ; h$ is thickness, $\mathrm{m} ; K_{W}$ is effective water permeability, $\mathrm{mD} ; \gamma$ is the shear rate, $\mathrm{s}^{-1}$.

The shear rate in the reservoir, based on Eq. (2), assuming that: 1) flow rate is $50 \mathrm{~m}^{3} / \mathrm{d} ; 2$ ) thickness is $10 \mathrm{~m}$; 3) permeability is $100 \mathrm{mD}$ and porosity is $20 \%$; and 4 ) radius is $0.1 ; 1 ; 10 ; 25$ and $100 \mathrm{~m}$.

\subsubsection{Rheological evaluation of the partially hydrolyzed polyacrylamide, Flopaam 3230S, degree of hydrolysis $30 \%$ and molar mass $5 \cdot 10^{6}$}

The polymer solution rheological study was made in a Brookfield viscosimeter, model LVT with ULA adapter, at the same target reservoir average shear rate: $10 \mathrm{~s}^{-1}$ in low flows $[1,2,4]$.

The rheological study compared the viscosity curve under standard conditions (distilled water at $298 \mathrm{~K}$ ) with the field condition using produced and injection water at $323 \mathrm{~K}$.

The effect of the salt content in the product rheological performance was achieved using also distilled water at $323 \mathrm{~K}$

The rheological study was also made with distilled water containing $\mathrm{Ca}^{++}$(55 ppm) and $\mathrm{Mg}^{++}$(24 ppm), added separately and together in the respectively mentioned concentrations. Furthermore, the polymer solution rheology was made with injection water, pure soft-water, soft-water with $10 \mathrm{ppm}$ of sodium hydrosulfite, and then soft-water with $50 \mathrm{ppm}$ of glutaraldehyde added.

\subsubsection{Rheological evaluation of Flopaam 32305 with different hydrolysis degree}

The polymers with 20 and $25 \%$ of hydrolysis were analyzed in the same equipment and conditions as that of $30 \%$ of hydrolysis, but in this case, the study was carried out only with the polymer dispersed in soft water with $10 \mathrm{ppm}$ of sodium hydrosulfite and $50 \mathrm{ppm}$ of glutaraldehyde.

\subsubsection{Flow test to evaluate the rock-fluid interaction}

Based on the flow tests two polymer-rock interaction parameters were determined: residual resistance 


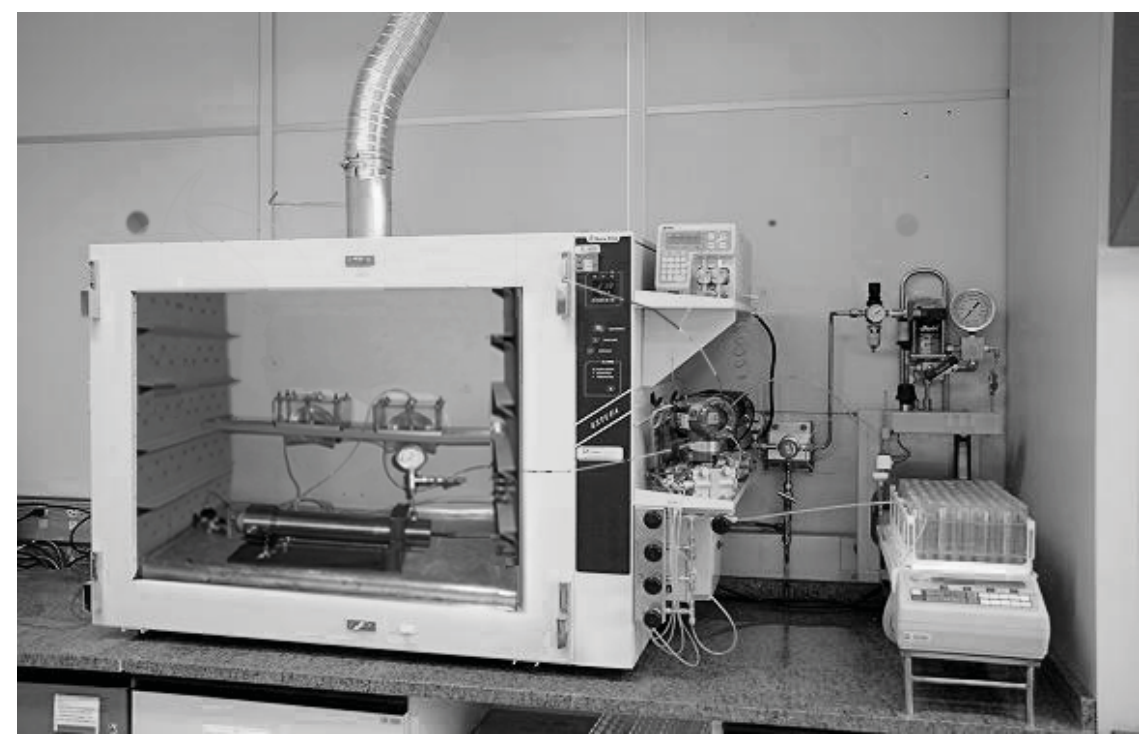

Fig. 1. Apparatus for porous media flow test

and total adsorption factors. These tests were performed in an experimental system (Fig. 1) where a constant flow pump (hydro pneumatic pump) injects the selected fluid through a set of valves. The injected fluid flows through the reservoir physical model, being confined in a steel jacket that simulates the upper layer pressures. Pressure, flow rate and temperature parameters are monitored throughout the test and the effluent is collected for later analysis. The polymer effluent quantity was measured by a spectrophotometer and the iodide (tracer) content, by a potentiometer.

The entire laboratory test defined up to now is important in the polymer selection and evaluation, but none of them eliminate the need to perform the flow tests. The porous media flow tests are the last laboratory evaluation stage of the polymer interaction with the reservoir, prior to the field tests. These tests have three objectives: to estimate the polymer recuperation efficiency in laboratory conditions (physical simulation); to input the simulation mathematics to estimate the gain (efficiency) of the field test in the same conditions (process scale-up); and to dimension the field test. The flow tests consist of a physical simulation of the field process and try to reproduce, on a reduced scale, the physical phenomena using the rock, the fluids (water and oil) and the temperature of the target reservoir. These tests are expensive (due to the use of original reservoir rocks) and are work and time consuming. The difficulties to mount and execute the tests include obtaining the reservoir rock sample, a cylindrical rock cut, the confinement of the rock in a steel jacket with pressure applications and the choice of the best sensors to monitor the flow rate, pressure, and temperature parameters (Fig. 1). One typical flow test involves the measurement of pressure and flow rate in real-time and the subsequent evaluation of the effluent. The effluent evaluation is the objective of the test, and normally involves the $\mathrm{pH}$ concentration measurement, etc. Based on these measured parameters the other required parameters can be calculated, which, in the case of the polymer, are divided into two groups: those calculated based on the pressure data and those based on the mass balance of the effluent $[2,11]$.

A- Parameters calculated based on pressure (measured in real-time)

Resistance Factor - The Resistance Factor $(R F)$, defined by the relationship between the water mobility and the polymer solution mobility (Eq. 3), is a parameter used to describe the polymeric solution mobility reduction during its passage from the polymer slug in relation to the water mobility. The mobility $(\lambda)$ of a fluid in a porous media is defined by the ratio between the rock permeability $(K)$ and the fluid viscosity $(\mu)$. The polymer mobility reduction is caused not only by the increase in viscosity but also by the permeability reduction of the formation caused by the polymer molecule retention in the pore throats. This retention causes a small modification in the porosity compared to the initial porosity, but as a consequence it has a big modification in the interface phenomenon, with a consequent pressure increase and permeability reduction $[1,2,4-7]$.

$$
R F=\frac{\lambda w}{\lambda p}=\frac{K W}{\mu w} \cdot \frac{\mu p}{K p}
$$

where: $R F$ is resistance factor; $\lambda w$ is water mobility; $\lambda p$ is polymer mobility; $K W$ is water permeability; $K p$ is polymer permeability; $\mu \mathrm{W}$ is water viscosity; $\mu p$ is polymer viscosity.

Residual Resistance Factor - The Residual Resistance Factor $(R R F)$ defined by the relationship between the water mobility before and after the polymer 
treatment (Eq. 4) is the parameter used to describe only the reservoir permeability reduction after the polymer flooding $[1,2]$.

$$
R R F=\frac{\lambda w b}{\lambda w a}=\frac{K w b}{\mu w} \cdot \frac{\mu_{w}}{k w a}=\frac{K w b}{K w a}=\frac{P a}{P b}
$$

where: $R R F$ is residual resistance factor; $\lambda w b$ is water mobility before the polymer; $\lambda$ wa is water mobility after the polymer; $K w b$ is water permeability before the polymer; $K w a$ is water permeability after the polymer; $\mu w$ is water viscosity; $P b$ is pressure during the water flow before the polymer treatment; $\mathrm{Pa}$ is pressure during the water flow after the polymer treatment.

In spite of the importance of the Resistance Factor $(R F)$ in the definition of the polymer capacity to drag oil in the passage moment from the water injection well, this parameter is not often used due to the operational limitation to measure the polymer permeability. The resistance factor is a function of the polymer permeability, which, in turn, is calculated based on the Darcy law [4-6] using a viscosity interpolated in the viscosity $\mathrm{x}$ shear rate plot, based on the estimated reservoir shear rate through empirical correlations. As could be seen earlier, the polymer has a pseudo-plastic behavior, that is, the polymer permeability is a function of the shear to which it is subjected. A critical point is the reservoir shear rate definition and its correlation with the rotational viscometer. Although many articles have been published on this subject, this is still a point of discussion. For this reason, the residual resistance factor $(R R F)$ is more often used in detriment to the resistance factor $(R F)$, mainly for data comparisons between the laboratory and the field, because the $R R F$ calculation is simpler, direct (relationship between the pressures, Eq. 4) and is devoid of simplifications $[1,2]$.

B- Parameters calculated based on the concentration profile (post treatment)

Adsorption - The term adsorption is often used to designate a joint action of the mechanical retention, caused by the polymer capture in the pore throats, and the physical-chemical adsorption, caused by the electrostatic attraction forces. The phenomena nomenclature of the adsorption / retention and the respective action mechanisms vary a little between authors $[4,12]$, however from the practical point of view what it is possible to quantify in the laboratory based on the flow test is the total irreversible adsorption through the analysis of the test effluent concentration profiles (mass balance).

In this way, the two principal parameters measured and compared were Residual Resistance Factor $(R R F)$ and the total irreversible adsorption in the reservoir rock. The total irreversible adsorption corresponds to the polymer total mass that remains in the porous media independent of the retention mechanism. This value is important for the polymer total mass calculation necessary in the field application.

The consumption of the polymer input volume during its passage is inevitable due to the adsorption / retention phenomenon of the molecules in the porous media. In practice what is sought is to make this phenomenon happen in a uniform and constant way avoiding localized blockages. The input volume also must be enough for all the area in question to be covered, but generating, at the end, (production well) the smallest residual possible to be disposed.

\section{Results and Discussions}

\subsection{Water Analysis}

The chemical compositions of the used waters are shown in Table 1, highlighting the high concentration of the calcium and magnesium ions, in the field waters, which were removed for the polymer application.

The production water analysis indicates a relatively low salinity when compared with original reservoir water: 200,000 ppm [21]. Such result demonstrates how much the reservoir had already been washed as well as its heterogeneity. The injection water presents a very low total salinity, however the presence of the calcium and magnesium ions are a concern to use the polymer. For the field application, the injection water was treated producing the soft water of same total salinity, however

Table 1

Analysis of the water samples

\begin{tabular}{|l|c|c|c|c|}
\hline Parameter & Units & ASTM & $\begin{array}{c}\text { Producti } \\
\text { on }\end{array}$ & Injection \\
\hline Barium & $\mathrm{mg} / 1$ & $\mathrm{D}-4382$ & 3.4 & 14 \\
\hline Bicarbonate & $\mathrm{mg} / \mathrm{l}$ & $\mathrm{D}-3875$ & 459 & 230 \\
\hline Bromide & $\mathrm{mg} / 1$ & $\mathrm{D}-4327$ & 30 & $<10$ \\
\hline Calcium & $\mathrm{mg} / 1$ & $\mathrm{D}-1976$ & 490 & 55 \\
\hline Chloride & $\mathrm{mg} / 1$ & $\mathrm{D}-512$ & 10380 & 60 \\
\hline Magnesium & $\mathrm{mg} / 1$ & $\mathrm{D}-1976$ & 198 & 24 \\
\hline pH & - & $\mathrm{D}-1293$ & 7.82 & 7.4 \\
\hline Potassium & $\mathrm{mg} / 1$ & $\mathrm{D}-1976$ & 85 & 5.4 \\
\hline Sodium & $\mathrm{mg} / 1$ & $\mathrm{D}-1976$ & 6215 & 7.2 \\
\hline $\begin{array}{l}\text { Total } \\
\text { salinity }\end{array}$ & $\mathrm{mg} / 1$ & $\mathrm{D}-512$ & 17091 & 87 \\
\hline Total solids & $\mathrm{mg} / 1$ & $\mathrm{D} 1193$ & 17892 & 475 \\
\hline $\begin{array}{l}\text { Viscosity } \\
\text { (298 K) }\end{array}$ & $\mathrm{cP}$ & $\mathrm{D}-445$ & 1.01 & 0.88 \\
\hline
\end{tabular}


without the divalent ions considered more harmful to the polymer.

\subsection{Reservoir Shear Rate Determination}

Defining the reservoir shear rate is an important point in the field application stage of the polymer injection process $[1,2,6]$. Throughout its flow in the rock formation the polymeric solution is subjected to different shears during its displacement process, which can influence the process in two ways. In the first case as the polymer has a Power Law behavior, the viscosity value varies with the shear. The second important point is the loss of viscosity due to the breakdown of the polymer chains caused by the mechanical stretching force during the flow, generally under high shearing. This degradation happens in two distinct situations: the first one - when the polymer has to pass through restricting pipelines and valves; and the second one - when the polymer is subjected to the flow in the porous media with its twists and bottlenecks in the pore throats.

Fig. 2 shows the distance between the injection and production wells that varies between $25 \mathrm{~m}$, in the reduced test, and $100 \mathrm{~m}$ in the larger test, which corresponds to the shear of $12 \mathrm{~s}^{-1}$ and $3 \mathrm{~s}^{-1}$, respectively. Therefore, considering that the average value cited in the literature is $10 \mathrm{~s}^{-1}$, this can also be adopted for this specific case.

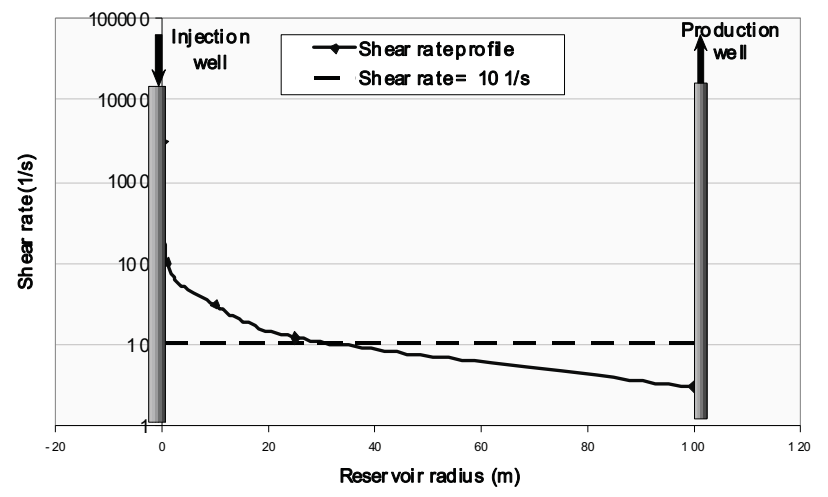

Fig. 2. Reservoir shear rate variation in function of the radius in a radial geometry

The polymer rheological behavior follows the Power Law model, where the viscosity varies with the shear rate that in turn varies with the distance from the water injection well to the oil production well. Therefore, it is fundamental to the rheological evaluation to estimate the average shear rate to which the polymer would be submitted. Based on a correlation described in the literature and the pilot project data, the average value of $10 \mathrm{~s}^{-1}$ was established [1, 2].

\subsection{Rheological Evaluation of the Polymer Fluids}

The polymer rheological performances in different waters are shown in Fig. 3. They are compared with the

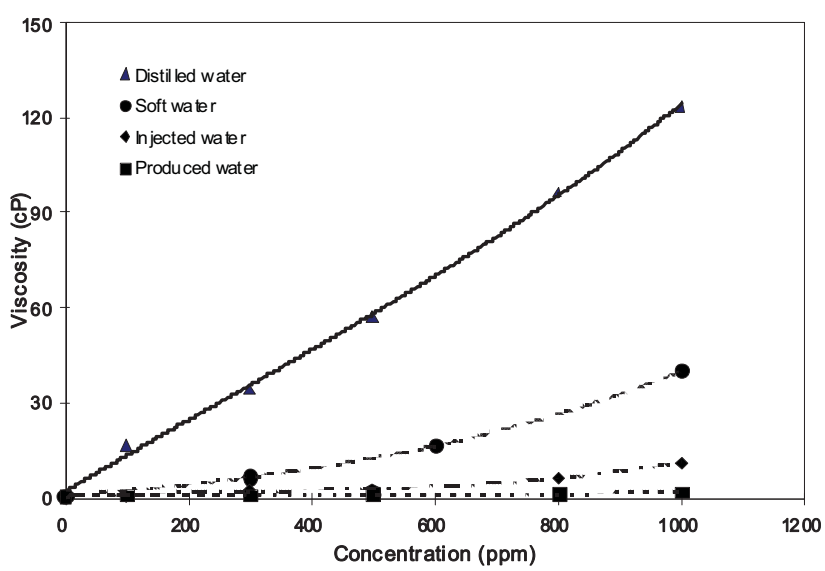

Fig. 3. Flopaam $3230 \mathrm{~S}$ polymer rheogram in pure distilled water, the soft water and target field injection and production water samples, at shear rate $10 \mathrm{~s}^{-1}$ and temperature of $323 \mathrm{~K}$

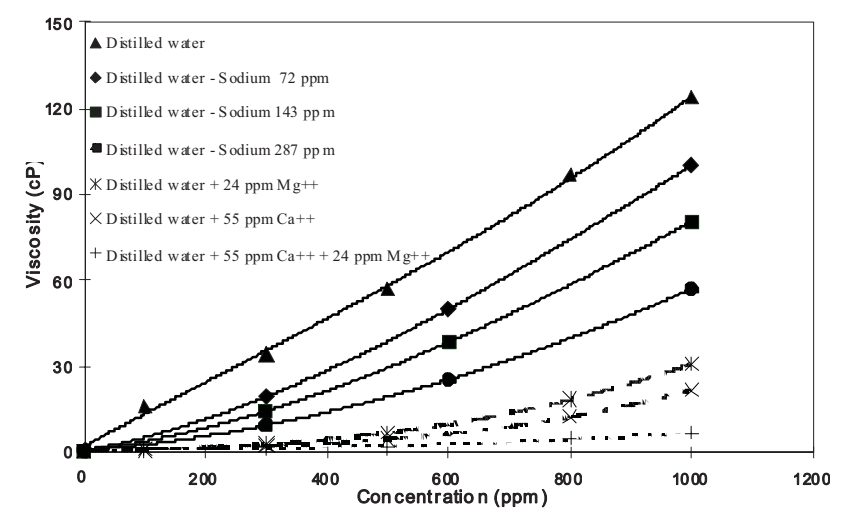

Fig. 4. Flopaam 3230S polymer rheogram in pure distilled water and in the presence of sodium and divalent cations, calcium and magnesium at shear rate $10 \mathrm{~s}^{-1}$ and temperature of $323 \mathrm{~K}$

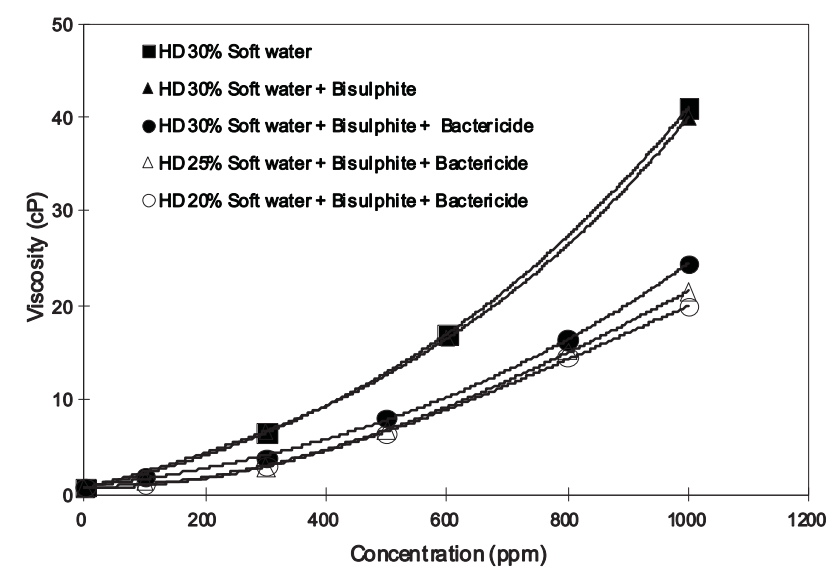

Fig. 5. Flopaam 3230 S polymer rheogram in soft water with additives, sodium hydrosulfite $10 \mathrm{ppm}$ and bactericide $50 \mathrm{ppm}$, with different hydrolysis degrees at $323 \mathrm{~K}$ and $10 \mathrm{~s}^{-}$ 
performance in distilled water. A distinct viscosity drop was observed in the injected and produced waters when compared with the distilled water. As the objective of the polymeric is to increase the viscosity, it was decided to remove the divalent ions of the water injected to approximate the behavior rheologically to the behavior in the distilled water.

The viscosities shown in Fig. 4 were inversely proportional to the salt content, probably due to a repulsion decrease of the polyacrylamide negative loads. It should be pointed out that the polymer is sensitive to the salinity. In this way, when the polymer solution contacts the reservoir, the viscosity will be reduced drastically due to larger salinity of the waters (mixture of the injection and original waters). Fig. 4 also proves the high sensibility of the product to the presence of the divalent cations, since it has been the decrease of the viscosity at the addition of the calcium and magnesium ions.

The polymer solution was tested in the presence of the additives usually used in the water injected in the reservoir. Fig. 5 shows that among the products added to the injection water, sodium hydrosulfite is used as an oxygen scavenger, to avoid the polymer degradation, and it does not practically interfere with the viscosity. However there seems to be an antagonism with the biocide, as seen in the polymer solution viscosity decrease.

The whole rheological study was carried out with $10 s^{1}$ and it confirmed the polymer high sensitivity to the divalent ions of calcium and magnesium, which are present in the formation water. This effect was observed in the growing viscosity drop of the polymer solutions in the distilled water, soft-water, injection water, and formation water. Based on this result it was decided to use treated field water in the field pilot project. The rheological study of this water showed that the best performance was achieved using the polymer with $30 \%$ hydrolysis degree The viscosity of the polyacrylamides solutions in this range of hydrolysis degree $(0-40 \%)$ increases with the increase of the hydrolysis degree [2]. This tendency is also observed in the polymer solution dissolved in the presence of addictive. All the viscosity plots were built in function of polymer concentration and they show that it was best to adjust the polynomial model degree 3 , according to the literature $[1,2]$.

Thus, the changes in the polymer characteristics were confirmed, such as hydrolysis degree and molar mass in the target reservoir conditions: temperature, injection water and additives, confirming the expected performance: $30 \mathrm{cp}$ (oil viscosity) at the calculated average shear rate $\left(10 \mathrm{~s}^{-1}\right)$ in the softened water and temperature of $323 \mathrm{~K}$ in the concentration of $1000 \mathrm{ppm}$. This polymer concentration is within the range usually used in this application type that is between 500 and 1500 for economical and logistics reasons.

\subsection{Flow Test to Evaluate the Rock-Fluid Interaction}

Table 2 shows the physical and petrophysical data of the reservoir sample used in the flow tests. The rock samples were saturated $100 \%$ with produced water of the field.

Table 2

Physical model data used in the flow tests 1 and 2

\begin{tabular}{|l|c|c|}
\hline \multicolumn{1}{|c|}{ Parameter } & \multicolumn{2}{c|}{ Value } \\
\hline Field sample & $\mathrm{A}$ & $\mathrm{B}$ \\
\hline Diameter, cm & 3.8 & 3.8 \\
\hline Length, cm & 7.3 & 7 \\
\hline Area, $\mathrm{cm}^{2}$ & 11.2 & 11.2 \\
\hline Total volume, $\mathrm{cm}^{3}$ & 81.5 & 77.7 \\
\hline Porous volume, $\mathrm{cm}^{3}$ & 14.7 & 16.1 \\
\hline Porosity, \% & 18 & 20.7 \\
\hline Air permeability, $\mathrm{mD}$ & 109 & 161 \\
\hline Water permeability, $\mathrm{mD}$ & 80 & 150 \\
\hline Water saturation, $\%$ & 100 & 100 \\
\hline
\end{tabular}

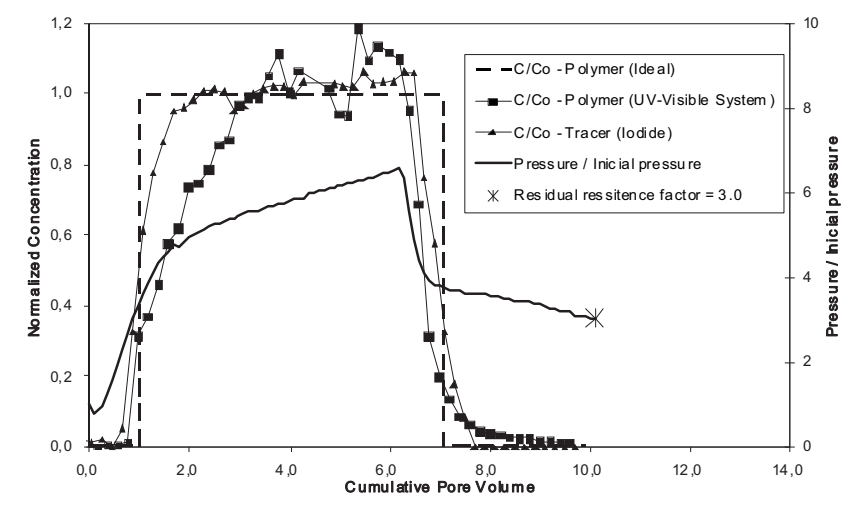

Fig. 6. Polymer concentration profiles in flow test 1 under the target reservoir conditions

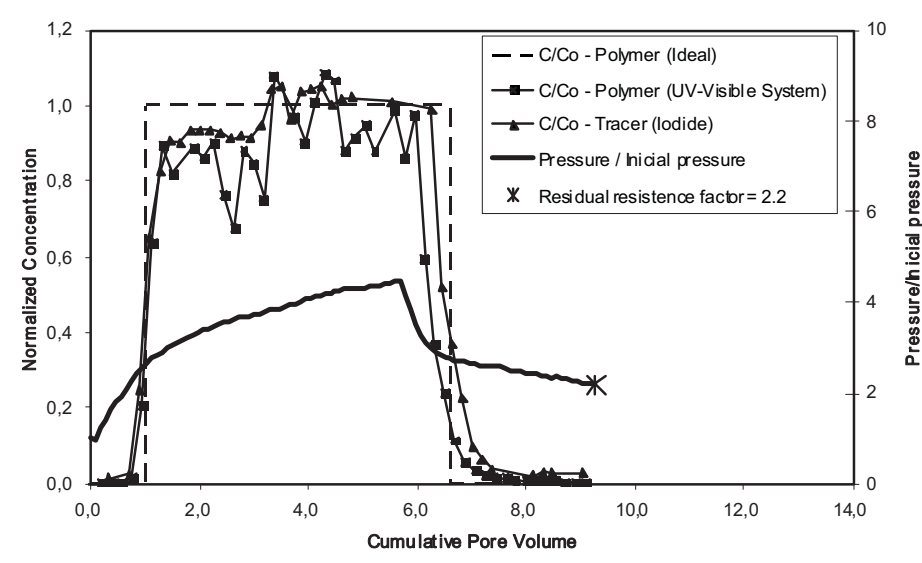

Fig. 7. Polymer concentration profiles in flow test 2 under the target reservoir conditions 
Table 3

Rock-fluid inter action results

\begin{tabular}{|l|c|c|}
\hline Parameter & \multicolumn{2}{|c|}{ Value } \\
\hline Test & 1 & 2 \\
\hline Sample & $\mathrm{A}$ & $\mathrm{B}$ \\
\hline $\begin{array}{l}\text { Residual resistance } \\
\text { factor }\end{array}$ & 3.0 & 2.2 \\
\hline Total adsorption, $\mu \mathrm{g} / \mathrm{g}$ & 31 & 20 \\
\hline
\end{tabular}

Figs. 6 and 7 show the concentration profiles that were obtained in two displacement tests with the selected polymer Flopaam 3230S in the target reservoir conditions. The residual resistance factor and total adsorption values obtained in the tests, as shown in Table 3, are within the range of values found in the literature [2]. The difference in the $R R F$ values between the two tests can be explained as the permeability difference between the different rock samples. In any case, both values are suitable for the required range. This implies the slight reduction in the effective permeability of the water, without prejudicing the injectability. This confirms that the molecular mass of five million is suitable for this application. Therefore, the dynamic evaluation, achieved in this study, confirmed the suitability of the polymer pre-selected in the previous stage: partially hydrolyzed polyacrylamide with $30 \%$ of hydrolysis degree and five million molar mass (Flopaam 3230S).

\section{Conclusions}

Based on the correlation described in the literature [6] and the pilot project data, the target reservoir average shear rate was established as $10 \mathrm{~s}^{-1}$. This was applied as the reference value for the whole rheological performance study, which showed that the polymer behavior follows the Power Law model.

As the target reservoir oil presents $30-50 \mathrm{cP}$ $(323 \mathrm{~K})$ viscosity, $30 \mathrm{cP}$ was considered as the mobility correction reference value. The reservoir water viscosity was $0.65 \mathrm{cP}$, at $323 \mathrm{~K}$, therefore the oil / water viscosity ratio changed from 46 to 1 due to the injected polymer [7, $8,11]$.

As the basic principle of the polymer injection process to increase production is the viscosity correction of the displacement phase, the choice of the soft water allowed the use of a smaller polymer concentration to achieve the required viscosity.

The polymer rheological performance was drastically reduced when dispersed in the injection or formation water when compared to that in distilled water mainly due to the presence of calcium and magnesium divalent ions. Therefore soft water-similar to the injection water but without the divalent cations - was chosen to dissolve and compose the polymer slug.
The soft water rheological tests and those with the additives used in the field showed that sodium hydrosulfite (oxygen scavenger) and principally the bactericide reduce the polymer solution rheological performance. This implies the use of higher concentration to achieve the desired viscosity ( $30 \mathrm{cP}, 373 \mathrm{~K}$ ).

The polymer rheological performance comparison between the pure soft water and soft water with additives in the range of hydrolysis degrees $(20 \%, 25 \%$ and $30 \%)$ showed that the best performance in fact occurs when the hydrolysis degree is $30 \%$, as indicated in the literature $[2,22]$.

For more operational simplicity the Residual Resistance Factor $(R R F)$ was calculated instead of Resistance Factor $(R F)$. K. Sorbie [2] considers the RRF values of 3.0 and 2.2, obtained in this study, appropriate for the application.

The total adsorption values obtained from the flow tests, 31 and $20 \mu \mathrm{g} / \mathrm{g}$ are considered a little high, being caused by the high clay content (28-32\%) of the formation. However, these results, although a little above literature [2] recommendations, did not interfere with the application, since the residual resistance factors obtained with the target reservoir sample flow tests were not high. On the other hand, these adsorption rates have to be taken into account in the optimum polymer concentration calculation.

The test results confirmed the suitability of the polymer preselected in the previous stage: partially hydrolyzed polyacrylamide, with $30 \%$ of hydrolysis degree and five million mass molar (Flopaam 3230s).

It is important to point out that the laboratory tests were conducted under as close target reservoir conditions as possible. Nevertheless, the actual field heterogeneity in relation to the oil, water and rock and the adverse viscosity conditions of the oil and water salinity leaves a doubt in relation to the process performance in the field. This scenario increases the importance of the injectivity tests and the close follow-up of the pilot project.

\section{References}

[1] Lake L.: Enhanced Oil Recovery. Prentice Hall, Englewood Cliffs, New Jersey 1989.

[2] Sorbie K.: Polymer-Improved Oil Recovery. CRC Press, Boca Raton, Florida 1991.

[3] Green D., Willhite W., and Paul G.: Enhanced Oil Recovery. SPE Textbookseries, V. 6. Richardson, Texas 1998.

[4] Chang H.: Fifth Symposium on IOR of the Society of Petroleum Engineers of AIME, Tulsa, Oklahoma, April 16-19 1978, SPE 7043.

[5] Needham R. and Peter H.: J. Petrol. Techn., 1987, SPE 17140.

[6] Dana G.: PhD thesis, University of Texas at Austin, 1989.

[7] Silva I., Melo M., Luvizotto J. and Lucas E.: SPE Latin American and Caribean Petroleum Engineering Conference, Buenos Aires, Argentina, April, 15-18, 2007, SPE 107727. 
[8] Melo M., Holleben C., Silva I. et al.: SPE Latin American and Caribean Petroleum Engineering Conference, Rio de Janeiro, Brasil, June 20-23, 2005, SPE 94898.

[9] American Petroleum Institute: Recommended Practices for Evaluation of Polymers Used in Enhanced Oil Recovery Operations, $1^{\text {st }}$ edn., 1990, RP 63.

[10] Melo M. and Lucas E.: Chem. \& Chem. Techn., 2008, 2, 295. [11] Melo M., Silva I. and Godoy G.:SPE/DOE Thirteenth Symposium on Improved Oil Recovery, Tulsa, Oklahoma, April 13-17, 2002, SPE 75194.

[12] Lecourtier J. and Chauveteau G.: 59 th $^{\text {th }}$ Annual Technical Conference and Exhibition, Houston, Texas, September 1619, 1984, SPE 13034.

[13] Du Y.: International Petroleum Conference, Puebla, Mexico, November 8-9, 2004, SPE 91787.

[14] Chatterji J. and Borchardt J.: 55 ${ }^{\text {th }}$ Annual Fall Technical Conference and Exhibition of the Society of Petroleum Engineers of AIME, Dallas, Texas, September 21-24, 1980, SPE 9288.

[15] Mezzomo R. and Vital C.: Petrobras Technical Bulletin, 1980, 24, 120.

[16] Mezzomo R. and Vital C.: Petrobras Technical Bulletin, 1981, 24, 184.

[17] Campbell T. and Bachman R.: First Annual Technical Meeting of South Saskat, Society of Petroleum of CIM, Regina, September 1985.

[18] Nars-El-Din H., Hawkins B. and Green K.: International Symposium on Oilfield Chemistry, Anaheim, California, February 20-22, 1991, SPE 21028.
[19] Shecaira F., Branco C., Souza A. et al.: SPE/DOE Improved Oil Recovery Symposium, Tulsa, Oklahoma, April 13-17, 2002, SPE 75170.

[20] Mezzomo R., Luvizotto J. and Palagi C.: SPE/DOE Improved Oil Recovery Symposium, Tulsa, Oklahama, April 3-5, 2000, SPE 59280.

[21] Candido A. and Wardlaw N.: Bulletin of Canadian Petroleum Geology, 1995, 3, 379.

[22] Kuliche W., Bose N. and Boudin M.: The Role of Polymers in Enhanced Oil Recovery. [in:] Stahl G. and Schulz D. (Eds.), Water-Soluble Polymers for Petroleum Recovery. New York 1988.

\section{ВИВЧЕННЯ УМОВ ВИКОРИСТАННЯ ПОЛІАКРИЛАМІДУ В НАФТОВИХ РЕЗЕРВУАРАХ: ФІЗИЧНЕ МОДЕЛЮВАННЯ ПОТОКУ В ПОРИСТОМУ СЕРЕДОВИЩ}

Анотація. Приведені розрахунки середньої ивидкості зсуву в резервуарах та реологічні дослідження полімерної дисперсності за певних умов. Визначено і охарактеризовано параметри взаємодії порода-флюїд з резервуаром, включаючи загальну адсорбиію і залищковий опір. Підтверджено, щуо запропонований полімер є придатним для иільового резервуару.

Ключові слова: полімер, поліакриламід, видобуток нафти, фізичне моделювання, взаємодія порода-флюїд, загальна адсорбиія, реологія. 